\title{
Synthesis of Gelatin-Cellulose Nanocrystals Hydrogel Membrane For Removal of Cu (II) And Co (II) From Mining Processes Wastewater
}

John Kabuba ( $\sim$ johnka@vut.ac.za )

Vaal University of Technology Faculty of Engineering and Technology

Trésor Lukusa

Vaal University of Technology Faculty of Engineering and Technology

\section{Research Article}

Keywords: Gelatin, Cellulose, nanocrystals, Copper (II) and Cobalt (II) removal, Adsorption, Hydrogel membrane

Posted Date: May 28th, 2021

DOl: https://doi.org/10.21203/rs.3.rs-383692/v1

License: (c) (i) This work is licensed under a Creative Commons Attribution 4.0 International License.

Read Full License 


\title{
Synthesis of Gelatin-cellulose nanocrystals Hydrogel Membrane for removal of $\mathrm{Cu}$ (II) and $\mathrm{Co}$ (II) from mining processes wastewater
}

\author{
John Kabuba* and Trésor Lukusa
}

Department of Chemical Engineering, Faculty of Engineering and Technology, Vaal University of Technology, Vanderbijlpark, Private Bag X021, South Africa Tel.: +27 16950 9887, Fax: +27 16950 9687, *E-mail: johnka@vut.ac.za

\section{Abstract}

This study describes the removal of $\mathrm{Cu}$ (II) and Co (II) ions from mining processes wastewater using synthesis of Gelatin-cellulose nanocrystals (CNCs) hydrogel membrane (GCHM). In a batch experiment, the influence of different parameters such as $\mathrm{pH}$, contact time, temperature, and ratio of gelatin and CNCs was evaluated. Higher removal efficiency was obtained at ratio $3 \div 1$ and at pH 5 and 7 for $\mathrm{Cu}$ (II) and $\mathrm{Co}$ (II), respectively, and a contact time of 120 mins and a temperature of $30^{\circ} \mathrm{C}$. The experimental data fitted satisfactory to Freundlich isotherm model. The adsorption of metal ions has been fit by the particle diffusion model. The results revealed that gelatin and CNCs were identified as the low-cost and promising adsorption material for the removal of heavy metals from wastewater.

KEYWORDS: Gelatin, Cellulose, nanocrystals, Copper (II) and Cobalt (II) removal, Adsorption, Hydrogel membrane.

\section{Introduction}

Heavy metals such as copper, cobalt, zinc, nickel, cadmium, and lead in wastewater from mining process are toxic, not biodegradable and pose several health problems even at low concentrations (Abdulrahman Oyekamni et al., 2019). Therefore, the removal of these heavy metals from wastewater is mandatory prior to its release into the environment. Conventional removal methods such as coagulation, flotation, solvent extraction, ion-exchange, reverse osmosis, bioremediation, electrodialysis and adsorption have been developed to remove copper and cobalt ions from wastewater (Abdulkareem et al., 2013; Garcia-Diaz et al., 2018; Kabuba, 2019; Kabuba et al., 2019). Adsorption is the most frequently used removal methods due to its low operating cost and possible regeneration of adsorbents (Garcia-Diaz et al., 2018). Different 
types of adsorption materials have been developed. Cellulose nanocrystals (CNCs) and gelatin were found to be the most materials used in adsorption methods (Akpomie et al., 2015; Silva Filho et al., 2013). Gelatin is low-cost protein, commercially available, biodegradable, filmforming properties, transparency and presenting good processibility obtained by the partial hydrolysis of collagen at controlled $\mathrm{pH}$ and temperature conditions (Joshi, Rawat \& Bohidar, 2018). CNCs are one of the most studied polysaccharide-based nanomaterials in polymer nanocomposites, biodegradable, and non-toxic characteristics (Noorbakhsh-Soltani, Zerafat \& Sabbaghi, 2018; Moon et al., 2011). CNCs were synthesized and incorporated in gelatin to increase the surface area which is required to improve the efficiency in the interaction with heavy metals ions (Oyewo et al., 2019; Leite et al., 2020). Hydrogel containing CNCs have good biocompatibility and biodegradability, can be used in water treatment as filtration membrane where the solution goes through the hydrogel membrane film as described for gel membrane permeation (Ahmed, 2015; Fujiyabu et al., 2017; Getachew et al., 2017; Marks et al., 2019; Tran et al., 2018; Yao et al., 2019). Due to the abundance of ion-coordinating sites and their aptitude to adsorb a large amount of water, hydrogel films have recently founded another application in water treatment to remove heavy metal ions using adsorption method (Alizadehgiashi et al., 2018; El-Halah and Lopez-Carrasquero, 2018; Perumal et al., 2019; Qi et al., 2019; Zhang et al., 2019). Literature review revealed that no work, in which efficiency of Gelatin-cellulose nanocrystals hydrogel membrane (GCHM) for the heavy metal ions removal from aqueous solution has been investigated. Therefore, the objective of this study was to determine the effects of various experimental variables for the removal of $\mathrm{Cu}$ (II) and $\mathrm{Cu}$ (II) onto GCHM.

\section{Materials and methods}

\section{Adsorbate, adsorbent preparation and sampling procedure}

Wastewater samples were collected from mining plant effluent in Rustenburg, South Africa. The samples were placed in $1000 \mathrm{~mL}$ plastic bottles, hold in cooler boxes and stored overnight in the fridge prior to the experiments. The characteristics of the wastewater used in the experiments is presented in Table 1.

All chemicals and reagents used in the work were analytical reagent grade purchased from Sigma-Aldrich, South Africa. Adequate quantities of CNCs and gelatin (purity $\geq 98 \%$ ) were supplied by CSIR and dispersed in $50 \mathrm{~mL}$ of water. The CNCs suspension was then homogenized using a homogenizer to ensure the CNCs suspended uniformly. Certain amount of gelatin was then added into $\mathrm{CNCs}$ suspension. The mixture was then stirred at $55^{\circ} \mathrm{C}$ until a 
homogeneous viscous mixture was obtained. Table 2 presented the ratios composition of GCHM hydrogel.

The cross-linking agent (EDTA 1\%) was then added drop wise. After 4 hours, the mixture was poured into a petri dish and placed in oven at $45^{\circ} \mathrm{C}$ until the mixture was dried. Hydrogels as films were removed from the petri dish and washed with distilled water to remove unreacted chemicals. The unreacted chemicals have been removed from hydrogel using acetone (Yao, 2019; Yin and Amin, 2014).

\section{Batch adsorption experiment}

The adsorption of $\mathrm{Cu}$ (II) and Co (II) ions by GCHM was tested in batch experiment. A shaker was used for mixing the solution. Several operational parameters were optimized, and this includes effects of $\mathrm{pH}$, gelatin-CNCs ratios, contact time and temperature. To ensure validity of the results and reputability, all experiments were performed in triplicate and the data were reported as an average value at $95 \%$ confidence level ( $\mathrm{p}>0.05)$. Heavy metal ions uptake capacity and the removal efficiency were calculated using Equations 1 and 2, respectively.

$q e=\frac{C o-C e}{m} \times V$

$\%$ removal $=\frac{\mathrm{Co}-\mathrm{Ce}}{\mathrm{Co}} \times 100$

where qe (mg/g): amount of metal ions adsorbed per unit mass of adsorbent, Co (mg/L): initial concentration of metal ions, $\mathrm{Ce}(\mathrm{mg} / \mathrm{L})$ : amount of metal ions at equilibrium, $\mathrm{V}(\mathrm{L})$ : volume of solution used and $\mathrm{m}(\mathrm{g})$ : mass of the adsorbent.

The experiments were carried out in $250 \mathrm{~mL}$ of plastic container, at a constant agitation speed (250 rpm) with $100 \mathrm{~mL}$ solution. Amount of $0.25 \mathrm{~g}$ of GCHM was added into $100 \mathrm{~mL}$ of binary metal ions solution and the mixtures were placed in a rotary shaker between 15 and 120 min. The effect of temperatures ranging between $30^{\circ} \mathrm{C}$ and $75^{\circ} \mathrm{C}$ was investigated using thermoshaker. The solution of binary metal ions was adjusted in $\mathrm{pH}$ solutions between 3 and 7 using $1 \mathrm{M}$ of $\mathrm{HCl}$ and $\mathrm{NaOH}$ solutions.

\section{Results and discussion}

\section{Characterization of Hydrogel}

The samples of cellulose, gelatin and their mixtures have been prepared on the disc of $\mathrm{CaF}_{2}$ and analysed to Midac FTIR 5000 Spectrophotometer. The absorption FTIR spectra obtained are shown in Figures 1-4.

The CNCs has shown the characteristic bands around 3000 and $3650 \mathrm{~cm}^{-1}$ that represents the strong elongation vibration band of the $\mathrm{OH}$ function. At $2950 \mathrm{~cm}^{-1}$, it is observed an elongation 
vibration band for bound $\mathrm{C}-\mathrm{H}$ that is confirmed by the deformation band around $1500 \mathrm{~cm}^{-1}$. The band around $1450 \mathrm{~cm}^{-1}$ is the vibration shear of $\mathrm{CH}_{2}$ (Alemdar and Sain, 2008; Sain and Panthapulakkal, 2006). The peak at $1700 \mathrm{~cm}^{-1}$ is characteristic of the elongation vibration band of the carboxyl $(\mathrm{C}=\mathrm{O})$ confirmed by the characteristic band around $890 \mathrm{~cm}^{-1}$ that corresponds to the $\mathrm{C}-\mathrm{H}$ of aldehyde group (Münster et al., 2017). The peak around $1000 \mathrm{~cm}^{-1}$ is attributed to $\mathrm{OH}$ function (Tran et al., 2018). The FTIR spectra of gelatin have present the characteristic peaks around of $2955 \mathrm{~cm}^{-1}$ for the vibration band of the amide $\mathrm{A}$, of $2700 \mathrm{~cm}^{-1}$ for the vibration band of the amide $\mathrm{B}$, of $1600 \mathrm{~cm}^{-1}$ for the vibration band of the amide (I), of $1500 \mathrm{~cm}^{-1}$ for the vibration band of the amide (I), of $1500 \mathrm{~cm}^{-1}$ for the vibration band of the amide (II) and of $1200 \mathrm{~cm}^{-1}$ for the vibration band of the amide (III). The amide (III) is represented by the combination of the elongation vibration peaks of $\mathrm{C}-\mathrm{N}$ and the deformation vibration peaks of $\mathrm{N}-\mathrm{H}$. Moreover, the amide (I) is characterized by the elongation vibration of $\mathrm{C}=\mathrm{O}$ to which is added a contribute band of elongation vibration of C-N, of deformation out-of-plan of C-C-N. Finally, the amide (II) is characterized by the elongation vibration band of C-N and that of outof-plane deformation of N-H out-of-plan (Merina et al., 2017; Fernandes de Almeida et al., 2012; Silvestein et al., 2007). The peaks below $1000 \mathrm{~cm}^{-1}$ are characteristic of low molecular weight amides (Silvestein et al., 2007).

After analyzing the FTIR spectra of gelatin and CNCs, the spectra of the mixtures of gelatin and $\mathrm{CNC}$ in proportions $\mathrm{A}, \mathrm{B}$, and $\mathrm{C}$ were analyzed (Fig. 3).

A comparison of the values of different bands shows a bathochromic effect coupled with a decrease in the intensity of certain bands (Feinsten, 1995). The bands are appearing between 2400 and $3600 \mathrm{~cm}^{-1}$ (N-H and O-H) for mix A which moves to 3000 and $3600 \mathrm{~cm}^{-1}$ for mix B up to $3240-3634 \mathrm{~cm}^{-1}$ for the mix $\mathrm{C}$. The same phenomenon is observed with the $\mathrm{C}=\mathrm{N}$ band which moves from $1490 \mathrm{~cm}^{-1}$, at $1550 \mathrm{~cm}^{-1}$ to $1650 \mathrm{~cm}^{-1}$ when moving from ratio $\mathrm{A}, \mathrm{B}$, and $\mathrm{C}$, respectively for the gelatin-cellulose mixture. In addition, they were observed a slight constancy of the carboxyl band at $1700 \mathrm{~cm}^{-1}$ except for the intensity of the band which increased slightly when going from ratio A to B.

The bathochromic effect observed with increasing gelatin content is evidence that new bonds are created and therefore new functions are created. Therefore, it observes the disappearance of certain bands and the decrease in the intensity of others. The optimum ratio appears to be that of the gelatin-cellulose of $75 \div 25$. Indeed, increasing the gelatin content could improve the quality and behaviour of the membrane. 
The SEM was used to observe the change in the morphological structure of the GelatinCellulose Hydrogel Membrane (GCHM), the SEM image of GCHM modified with EDTA was presented in Figures 5A, 5B, and 5C. The images were taken by applying $4 \mathrm{kV}$ voltage with different magnification times for the clarification of the surface. The SEM images of GCHM powder before adsorption were studied in Figure 5.

Porosity characterization is based on the presence of open pores which are related to properties such as permeability and surface area of the porous structure. The SEM image indicates the presence of bigger particles with irregular shapes (Figs. 5A and 5B). Figure 5C shows the cavities of different shapes and sizes, and larger pores between the particles could be observed which will be helpful for the solution permeating through the GCHM (Wang et al., 2018).

The high porosity provides a favourable adsorption of copper and cobalt ions (Hossan et al., 2014). The presence of such granules increases the surface area of the composite which is suitable for effective adsorption of metal ions. A visible change in surface morphology can be observed following adsorption. Small openings and holes on the surface increase the contact of the adsorption and therefore lead to pore diffusion during the adsorption process (Kabuba and Banza, 2020). A morphology that changes as the gelatin concentration increases (Fig. 5C $>$ Fig. 5B > Fig. 5A) and consequently, several pores have been observed.

\section{Effect of $p H$}

While adsorption process, the surface charge of the adsorbent can change according to the acidic or alkali medium of solution $\mathrm{pH}$. Figure 6 indicates that the adsorption of copper and cobalt ions has been sensibly affected by the values of $\mathrm{pH}$. It has been observed that the removal efficiency was low for the $\mathrm{pH}$ values from 0 to 4 and increase for the $\mathrm{pH}>4$.

Kumaruzaman et al., (2017) and El-Sheikh et al., (2012) has shown that the pH in the range of $3-5$ (acidic medium), there is a strong activity of protons $\left(\mathrm{H}^{+}\right)$that compete with the metal ions at the functional groups onto GCHM and also the electrostatic repulsion between $\mathrm{Cu}$ (II) and $\mathrm{Co}$ (II) in solution. The maximum removal percentage of $\mathrm{Cu}$ (II) and $\mathrm{Co}$ (II) was obtained at $\mathrm{pH} 5$ and 7 for copper and cobalt ions, respectively; therefore $\mathrm{pH} 5$ and 7 have been selected for all the experiments in this study.

\section{Effect of Gelatin-CNCs ratios}

The effect of gelatin and CNCs ratios have played a big role on the percentage removal of both ion metals at different values of pHs. Figure 7 shows the effect of gelatin and $\mathrm{CNCs}$ ratio on the removal of $\mathrm{Cu}$ (II) and $\mathrm{Co}$ (II). 
The result in Figure 7 shows that the percentage removal of both ion metals increased with increased of gelatin amount. The high percentage removal was 70.5 and $72.5 \%$ for $\mathrm{Cu}$ (II) and Co (II) at pH 5 and 7, respectively for the ratio of $3 \div 1$. Swelling of hydrogel has been observed by Yin \& Amin (2014) for $\mathrm{pH} \geq 7$ (Kamaruzaman et al., 2017). It is attributed to the presence of loan pairs from amino acid of gelatin. The electrical charge of hydrogel at $\mathrm{pH} 5$ is almost equal to zero because of isoelectric point of gelatin $(\mathrm{pI}=4.9)$ due to amino-acid function that does not facilitate the GCHM's swelling. Above the isoelectric point, the network is negatively charged forming anionic gel. This situation can explain why the percentage removals of copper and cobalt metals ions is low and almost closer to pH 5 (Fig. 7A).

\section{Effect of contact time}

Figure 8 represents the effect the effect of time on the percentage removal of copper and cobalt ions. Adsorption process occurred by using a thermo-shaker at the range time of $15-120$ minutes; $0.25 \mathrm{~g}$ of GCHM for $100 \mathrm{~mL}$ of wastewater for an initial concentration of $100 \mathrm{mg} / \mathrm{L}$. It has been reported by Liu et al. (2015) that the percentage removal was function of contact time.

The percentage removal of $\mathrm{Cu}$ (II) and $\mathrm{Co}$ (II) ions was low at time $\mathrm{t}=0 \mathrm{~min}$ and progressively increase until equilibrium ( $\mathrm{t}=120 \mathrm{~min})$ that means, there is many available activated sites on the surface of GCHM that can adsorb copper and cobalt ions (Hossan et al., 2014). Compared with the adsorptions of $\mathrm{Cu}$ (II) and Co (II) to other adsorbents (Al-Shahrani, 2014; Hossan et al., 2014), the sorption equilibrium has not been reached quickly. This can be due to the low adsorption capacity of GCHM or can be attributed also to high initial concentration of $\mathrm{Cu}$ (II) and Co (II) and the mass adsorbent $(0.25 \mathrm{~g} / 100 \mathrm{~mL})$.

\section{Effect of temperature}

It has been observed in Figure 9 that the negative effect of the temperature on the adsorption of $\mathrm{Cu}$ (II) and Co (II) onto GCHM. The percentage removal decreases while the temperature increases from $30^{\circ} \mathrm{C}-70^{\circ} \mathrm{C}$.

The percentage removal of $\mathrm{Cu}$ (II) and Co (II) was decreased from 70.5 to $30.8 \%$ and from 63.8 to $24.1 \%$ at $\mathrm{pH} 5$ for $\mathrm{Cu}$ (II) and $\mathrm{Co}$ (II), respectively. At pH 7, the percentage removal decreases from 69.1 to $27 \%$ and from 74.5 to $32.2 \%$ for $\mathrm{Cu}$ (II) and Co (II), respectively. The adsorption process was an endothermic process because the removal capacity decreases while the temperature increases and this means that the available activated site onto GCHM decrease (Reshtnyak et al., 2012). It was observed the disintegration of GCHM while temperature was 
gradually increased, and the filtration become difficult after adsorption process. This is the reason why is better to work with the less temperature. Therefore, the temperature of $30^{\circ} \mathrm{C}$ was chosen to run all the experiments.

\section{Adsorption isotherms}

Adsorption equilibrium data of $\mathrm{Cu}$ (II) and $\mathrm{Co}$ (II) - GCHM system have been investigated using three different isotherm models.

\section{Langmuir isotherm (see Eqs. 3 and 4)}

$$
\begin{aligned}
\frac{C e}{q e} & =\frac{1}{q m K L}+\frac{C e}{q m} \\
R L & =\frac{1}{1+K L C o}
\end{aligned}
$$

where $C_{e}$ is equilibrium metal concentration; $q_{m}$ is the adsorption maximum capacity $(\mathrm{mg} / \mathrm{g})$, $\mathrm{K}_{\mathrm{L}}$ Langmuir constant $(\mathrm{L} / \mathrm{mg}), \mathrm{q}_{\mathrm{e}}$ is the amount of metal ion adsorbed at equilibrium and $\mathrm{R}_{\mathrm{L}}$ is a constant of separation (Mobashespour et al., 2014; Blahovec and Yanniotic, 2009).

\section{Freundlich isotherm (Eq. 4)}

$$
\ln q e=\ln K f+\frac{1}{n} \ln C e
$$

where $\mathrm{C}_{\mathrm{e}}$ is the amount of metal at equilibrium $(\mathrm{mg} / \mathrm{L})$; $\mathrm{q}_{\mathrm{e}}$ : amount of metal adsorbed at per unit mass at equilibrium (mg/g), n: Freundlich constant describing the affinity of metal for the adsorbent and $\mathrm{K}_{\mathrm{f}}$ : Freundlich constant.

\section{Dubinin-Radushkevich isotherm (see Eqs. 6, 7 and 8)}

$$
\begin{aligned}
& \operatorname{lnqe}=\ln \mathrm{q}_{\mathrm{m}}-\beta \psi^{2} \\
& \psi=\mathrm{RT} \ln \left(1+1 / \mathrm{C}_{\mathrm{e}}\right) \\
& \mathrm{E}=\frac{1}{\sqrt{2} \beta}
\end{aligned}
$$

where $\mathrm{q}_{\mathrm{m}}(\mathrm{mg} / \mathrm{g})$ : metal maximum adsorption capacity, $\psi$ : Polanyi potential and $\beta\left(\mathrm{mol}^{2} / \mathrm{J}^{2}\right)$ : coefficient related to free energy of adsorption, $\mathrm{E}(\mathrm{kJ} / \mathrm{mol})$ : energy, R: universal gas constant $\left(8.314 \mathrm{~mol}^{-1} \mathrm{~K}^{-1}\right)$.

The best fit for an isotherm is giving by an $\mathrm{R}^{2}$ closest to 1 . The adsorption isotherms for $\mathrm{Cu}$ (II) and Co (II) were studied using ratio $3 \div 1$ for a mass of $0.25 \mathrm{~g}$ at $303 \mathrm{~K}$. The data obtained from linear Langmuir, Freundlich and D-R isotherms plot from the adsorption of $\mathrm{Cu}$ (II) and Co (II) onto GCHM are presented in Table 3. 
222 The results reported in Table 3 indicate that $\mathrm{Cu}$ (II) and $\mathrm{Co}$ (II) fit the experimental data for the

223 Freundlich isotherm model. The monolayer adsorption capacities of hydrogel for $\mathrm{Cu}$ (II) and

224 Co (II) are 5.85 and $10.99 \mathrm{mg} / \mathrm{g}$, respectively. Cu (II) and Co (II) shows a good affinity and

225 have been favourable to be adsorbed by hydrogel because $1<\mathrm{n}>10$. The Freundlich constant 226 were 0.83 and 1.31, respectively for $\mathrm{Cu}$ (II) and Co (II) (Akpomie et al., 2015). Adsorption 227 process has been favourable to the Langmuir model because the $\mathrm{R}_{\mathrm{L}}$ value was 0.23 and 0.16 228 for both metal ions (Garcia-Diaz et al., 2018).

229

230 231

232

233

234

235

236

237

238

239

240

241

242

243

244

245

246

247

248

249

250

251

\section{Kinetic studies}

The kinetic parameters for the adsorption process were studied on the batch adsorption at $\mathrm{pH}$ 5 and 7 at $303 \mathrm{~K}$.

\section{Pseudo first order model (see Eq. 9)}

$\log \left(\mathrm{q}_{\mathrm{e}}-\mathrm{q}_{\mathrm{t}}\right)=\log \mathrm{q}_{\mathrm{e}}-\left(\mathrm{k}_{1} \mathrm{t} / 2.303\right)$

\section{Pseudo second order model (see Eq. 10)}

$1 / \mathrm{q}_{\mathrm{t}}=\left(1 / \mathrm{k}_{2} \mathrm{qe} \mathrm{e}^{2}\right) \mathrm{t}+\left(1 / \mathrm{q}_{\mathrm{e}}\right)$

where $\mathrm{q}_{\mathrm{e}}$ : amount of metal at adsorbed at equilibrium, $\mathrm{q}_{\mathrm{t}}$ : amount metal adsorbed at a $t$ time $(\mathrm{mg} / \mathrm{g})$ and $\mathrm{k}_{1}$ and $\mathrm{k}_{2}$ : rate constant of the reaction $\left(\mathrm{min}^{-1}\right)$ for first and second order, respectively (Fosso-Kankeu, 2018).

From the values of $\mathrm{R}^{2}$ represented in Table 4, it was observed that both metal ions are fitting the pseudo first order kinetic.

\section{Kinetic diffusion}

Kinetic diffusion mechanism has been investigated in order to determine the nature of adsorption of $\mathrm{Cu}$ (II) and Co (II) to the interface of GCHM. Three transport processes were investigated as film diffusion (see Eq. 11), particle diffusion (see Eq. 12) and moving boundary (see Eq. 13) (Garcia-Diaz et al., 2018).

$\ln \left(1-\frac{q t}{q e}\right)=-K t$

$\ln \left[1-(q t / q e)^{2}\right]=-K t$

$3-3[1-(q t / q e)]^{\frac{2}{3}}-2 \frac{q t}{q e}=K t$

where $\mathrm{K}(1 / \mathrm{min})$ is the rate constant model, $\mathrm{q}_{\mathrm{e}}$ and $\mathrm{q}_{\mathrm{t}}(\mathrm{mg} / \mathrm{g})$ are the sorption capacities at equilibrium and contact time, respectively, and $t$ is time (min). 
The moving boundary, particle diffusion and film diffusion model of $\ln (1-F)$ versus time were taken for $\mathrm{Cu}$ (II) and $\mathrm{Co}$ (II) ions and presented in Table 5 at $\mathrm{pH} 5$ and 7 . The regression coefficient $\left(\mathrm{R}^{2}\right)$ values of 0.98 for $\mathrm{Cu}$ (II) and 0.91 for Co (II) have shown a good fit of film diffusion. The results obtained by kinetic diffusion show that the adsorption of both metal ions onto GCHM could be better explained by the film diffusion model where the rate constant models are $0.032 / \mathrm{min}$ for $\mathrm{Cu}$ (II) and $0.046 / \mathrm{min}$ for $\mathrm{Co}$ (II).

\section{Thermodynamic studies}

$\Delta \mathrm{G}^{\circ}=-\mathrm{RT} \ln \mathrm{K}_{\mathrm{d}}$

$\mathrm{K}_{\mathrm{d}}$ is equilibrium constant that can be used to determine the thermodynamic parameters $\left(\mathrm{H}^{\circ}\right)$ enthalpy, $\left(\mathrm{S}^{\circ}\right)$ entropy and $\left(\mathrm{G}^{\circ}\right)$ free energy, $\mathrm{R}(8.314 \mathrm{~J} / \mathrm{mol} \mathrm{K})$ universal gas constant and $\mathrm{T}$ is the temperature (K) (Sandoval-Flores et al., 2018).

$\Delta \mathrm{G}^{\circ}=\Delta \mathrm{H}^{\circ}-\mathrm{T} \Delta \mathrm{S}^{\circ}$

$\mathrm{K}_{\mathrm{d}}=\mathrm{q}_{\mathrm{e}} / \mathrm{C}_{\mathrm{e}}$

$-\ln \mathrm{K}_{\mathrm{d}}=\left(\Delta \mathrm{H}^{\circ} / \mathrm{R}\right) \cdot 1 / \mathrm{T}-\left(\Delta \mathrm{S}^{\circ} / \mathrm{R}\right)$

The values of $\Delta \mathrm{H}^{\circ}$ and $\Delta \mathrm{S}^{\circ}$ from the slope and intercept of the $\ln \mathrm{K}_{\mathrm{d}}$ versus $1 / \mathrm{T}$ through the Von't Hoff line Equation's (Hino et al., 2010).

The thermodynamic parameter values are summarized in Table 6 . The negative values of $\Delta \mathrm{G}^{\circ}$ obtained almost at all temperatures for both metal ions indicate that the adsorption process was spontaneous. It was also observed that the change in $\Delta^{\circ} \mathrm{G}$ increase with increase in temperature suggesting that higher temperatures is not making the adsorption easier. The positives values of $\Delta \mathrm{H}^{\circ}$ indicate an endothermic process. In physical adsorption process, the $\Delta \mathrm{H}^{\circ}<40$ $\mathrm{kJ} / \mathrm{mol}$.K. (Akpomie et al., 2015). The value of $\Delta \mathrm{H}^{\circ}$ obtained from both metal ions showed a physical adsorption process onto the surface of GCHM. This physical adsorption explains the reason why the kinetic data did not fit the pseudo second order (chemical sorption). In addition, the positive values of $\Delta \mathrm{H}^{\circ}$ indicated that the adsorption process of both metal ions was endothermic (Hino et al., 2010). Positive values of $\Delta \mathrm{S}^{\circ}$ indicate an increase in randomness at the solid/liquid interface during adsorption. The positive value of $\Delta \mathrm{S}^{\circ}$ indicated that the reflected the affinity of GCHM for $\mathrm{Cu}$ (II) and $\mathrm{Co}$ (II) and suggested some structural changes in GCHM. 


\section{Conclusion}

282 The results obtained in this study prove that GCHM is a potential and useful low-cost material 283 for the removal efficiency of $\mathrm{Cu}$ (II) and Co (II) ions from mining processes wastewater. 284 Optimum removal of both heavy metal ions was obtained at ratio $3 \div 1$ and at $\mathrm{pH} 5$ and 7 for $\mathrm{Cu}$ 285 (II) and Co (II), respectively and a contact time of 120 mins was utilized for equilibrium 286 removal. Freundlich isotherm model gave the best fit to the experimental data for both metal 287 ions. The positive values of $\Delta \mathrm{H}^{\circ}$ indicate that the process was endothermic, negative values of $288 \Delta \mathrm{G}^{\circ}$ showed the spontaneous nature of the process and positive values of $\Delta \mathrm{S}^{\circ}$ reflect an 289 increase in randomness during the adsorption $\mathrm{Cu}$ (II) and Co (II) onto GCHM. Kinetic of 290 adsorption of heavy metal ions onto GCHM was effectively described by pseudo first order 291 and physical nature adsorption.

292

293

294

295

296

297

298

299

300

301

302

303

304

305

306

307

\section{Credit Authorship contribution statement}

JK analysed the conceptualization, methodology, validation, formal analysis, investigation, data curation, writing - original draft, writing - review \& editing, visualization, resources.

TL performed the methodology, validation, investigation, formal analysis, data curation, writing - original draft.

\section{Declaration of competing interest}

The authors have declared no conflict of interest.

Ethical approval: Not applicable.

Consent to participate: Not applicable.

Consent to publish: Not applicable.

Funding: Not applicable.

Availability of data and material: Not applicable.

\section{References}

Abdulkareem SA, Muzenda E, Afolabi AS, Kabuba J. (2013). Treatment of Clinoptilolite as an Adsorbent for the removal of Copper ion from synthetic wastewater solution. Arab J Sci Eng. 38: 2263 - 2272. http://doi.org/10.1007/s13369-012-0505-X. 
Abdulrahman Oyekanmi A, Abd Latiff AA, Daud Z, Saphira Radin Mohamed RM, Ismail N, Ab Aziz A, Rafatullah M, Hossain K, Ahmad A, Kamoldean Abiodun A. (2019). Adsorption of cadmium and lead from palm oil mil effluent using bone-composite: optimisation and $\begin{array}{llllll}\text { isotherm } & \text { studies. Int } \mathbf{J} \text { Env Anal Chem. 99: }\end{array}$ https://doi.org/10.1080/03067319.2019.1607318

Ahmed EM. (2015). Hydrogel: Preparation, characterization, and applications: A review, J Advance Res. 6: 105 - 112. https://doi.org/10.1016/j.jare.2013.07.006.

Akpomie KG, Dawodu FA, Adebowale KO. (2015). Mechanism on the sorption of heavy metals from binary-solution by a low cost montmorillonite and its desorption potential, Alexandria Eng J. 54: 757 - 767. https://doi.org/10.1016/j.aej.2015.03.025.

Alemdar A, Sain M. (2008). Isolation and characterization of nanofibres from agricultural residues-wheat straw and soy hulls, Bioresource Technol. 6: 1664 - 1671. doi.org/10.1016/j.biortech.2007.04.029.

Alizadehgiashi M, Khuu N, Khabibullin A, Henry A, Tebbe M. (2018). Nanocolloidal hydrogel from heavy metal scavenging. Nanotechnology. 12: 8160 - 8168. https://doi.org/10.1021/acsnano.8b03202.

Al-Shahrani SS. (2014). Treatment of wastewater contaminated with cobalt using Saudi activated bentonite. Alexandria Eng J. 53: 205 -211. https://doi.org/10.1016/j.aej.2013.10.006.

Blahovec J, Yanniotis S. (2009). Modified classification of sorption isotherms. J Food Eng. 91: 72 - 77. https://doi.org/10.1016/j.jfoodeng.2008.08.007.

El Halah A, López-Carrasquero F, Contreras J. (2018). Applications of Hydrogels in the adsorption of metallic ions, Ciencia e Ingenieria. 39:1 - 28.

El-Sheikh R, Hefni HH, El-Farargy AF, Bekhit M, Negm NA. (2012). Adsorption Efficiency of Chemically modified Chitosan towards copper and cobalt Ions from Industrial Waste Water, Egyptian J Chem. 55 (3): 291 - 305. https://doi:10.21608/ejchem.2012.1156.

Feinsten R. (1995). Guide to spectroscopic identification of organic compound, CRC Press Boca Raton-London-New York, 124. 
Fernandes de Almeida P, da Silva Lannes SD, Araújo Calarge F, de Brito Farias TM, Santana JCC. (2012). FTIR Characterization of Gelatin from chicken Feet. J Chem Chem Eng. 6: 1029 -1032 .

Fosso-Kankeu E. (2018). Synthesized af-PFCl and GG-g-P(AN)/TEOS hydrogel composite used in hybridized technique applied for AMD treatment. Phys Chem Earth, Parts A/B/C. 105: 170 - 176. https://doi.org/10.1016/j.pce.2018.02.015

Fujiyabu T, Li X, Shibayama M, Chung U, Sakai T. (2017). Permeation of water through Hydrogels with controlled network structure. Macromolecules. 50: 9411 - 9416. https://doi.org/10.1021.

Garcia-Diaz I, López FA, Alguacil FJ. (2018). Carbon Nanofibers: Anew Adsorbent for copper removal from wastewater. Metals. 8: 914 - 927. https://doi.org/10.3390/met8110914.

Getachew BA, Kim S-R, Kim J-H. (2017). Self-healing Hydrogel pore-filled water filtration Membranes. Environ Sci Technol. 51: 905 - 913. https://doi.org/10.1021/acs.est.6b04574.

Hino S, Ichikawa T, Kojima Y. (2010). Thermodynamic properties of metal amides determined by ammonia pressure-composition isotherms. J Chem Thermodynam. 42: $140-143$. https://doi.org/10.1016/j.jct.2009.07.024.

Hossan MJ, Gafur MA, Kadir MR, Karim MM. (2014). Preparation and characterization of gelatin-hydroxyapatite composite for bone tissue engineering. Polymer Composites. 14: 24 32. https://doi.org/10.1002/pc.23725.

Kabuba J. (2019). Equilibrium Ion-Exchange studies of $\mathrm{Na}^{+} / \mathrm{Cu}^{2+}$ and $\mathrm{Na}^{+} / \mathrm{Co}^{2+}$ on Clinoptilolite in Industrial Wastewater. Eng Letters. 27: 467 - 474.

Kabuba J, Banza M. (2020). Modification of clinoptilolite with dialkylphosphinic acid for the selective removal of cobalt (II) and nickel (II) from hydrometallurgical effluent. Can J Chem Eng. https://doi: 10.1002/cjce.24005.

Kabuba J, Mulaba-Bafubiandi A, Battle K. (2014). Neural Network technique for modelling of $\mathrm{Cu}$ (II) removal from aqueous solution by clinoptilolite, Arab J Sci Eng. 39: 6793 - 6803. https://doi.org/10.1007/s13369-014-1277-2.

Kamaruzaman S, Aris NIF, Yahaya N, Hong LS, Razak MR. (2017). Removal of Cu (II) and Cd (II) ions from Environmental Water Samples by using Cellulose Acetate Membrane. J Environ Analytical Chem. 4: 1 - 8. https://doi: 10.4172/2380-2391.1000220. 
Leite LSF, Moreina FKV, Mattoso LHC, Bras J. (2020). Electrostatic interactions regulate the physical properties of gelatin-cellulose nanocrystals nanocomposite films intended for biodegradable packaging. Food

Hydrocolloids. https://doi.org/10.1016/j.foodhyd.2020.106424.

Liu P, Borrell PF, Božič M, Kokol V, Oksman K. (2015). Nanocelluloses and their phosphorylated derivatives for selective adsorption of $\mathrm{Ag}^{+}, \mathrm{Cu}^{2+}$ and $\mathrm{Fe}^{3+}$ from industrial effluents. J. Hazard Mat. 294: 177 - 185. https://doi.org/10.1016/j.jhazmat.2015.04.001.

Joshi N, Rawat K, Bohidar HB. (2018). pH and ionic strength induced complex coacervation of Pectin and Gelatin A. Food Hydrocolloids. 74: 132-138. https://doi. org/10.1016/j.foodhyd.2017.08.011.

Marks R, Seaman J, Peresz-Calleja P, Kim J, Nerenberg R, Doudrick K. (2019). Catalytic Hydrogel Membrane reactor for aqueous contaminants. Environ Sci Technol. 53: 6492 - 6500. https://doi.org/10.1021/acs.est.9b01667.

Merina Paul Das, Suguna PR, Karpuram Prasad, Vijaylakshmi JV, Renuka M. (2017). Extraction and characterization of gelatin: a functional biopolymer. Int J Pharm Pharm Sci. 9: 9, 239. https://doi: 10.22159/ijpps.2017v9i9.17618.

Mobasherpour I, Salahi E, Ebrahimi M. (2014). Thermodynamics and kinetics of adsorption of $\mathrm{Cu}$ (II) from aqueous solutions onto multi-walled carbon nanotubes, J Saudi Chem Soc. 18: 792 - 801. https://doi.org/10.1016/j.jscs.2011.09.006.

Moon RJ, Martini A, Nairn J, Simonsen J, Youngblood J. (2011). Cellulose nanomaterials review: structure, properties and nanocomposites. Chem. Soc. Rev. 40: 3941-3994. https://doi.org/10.1039/C0CS00108B.

Münster L, Vicha J, Klofac J, Masar M, Kucharczyk P, Kuritka I. (2017). Stability and aging of solubilized dialdehyde cellulose. Cellulose. 24: 1 - 14. https://doi.org/10.1007/s10570-017$1314-\mathrm{x}$

Noorbakhsh-Soltani SM, Zerafat MM \& Sabbaghi S. (2018). A comparative study of gelatin and starch-based nano-composite films modified by nano-cellulose and chitosan for food packaging applications. $\quad$ Carbohydrate $\quad$ Polymers, $\quad 189: \quad 48-55$. https://doi.org/10.1016/j.carbpol.2018.02.012. 
Oyewo OA, Mutesse B, Leswifi TY, Onyango MS. (2019). Highly efficient removal of nickel and cadmium from water using Sawdust-derived cellulose nanocrystals. J Environ Chem Eng. 7:103251. https://doi.org/10.1016/j.jece.2019.103251.

Perumal S, Atchudan R, Yoon DH, Joo J, Cheong IW. (2019). Spherical chitosan-gelatin hydrogel particles for removal of multiple heavy metal ions from wastewater. Ind Eng Chem Res. 58: 9900 - 9907. https://doi.org/10.1021/acs.iecr.9b01298.

Qi X, Lin L, Shen L, Li Z, Qin T, Qian Y, Wu X, Wei X, Gong Q, Shen J. (2019). Efficient Decontamination of lead ions from wastewater by salecan polysaccharide-based Hydrogels. Sustainable Chem Eng. 7: 11014 - 11023. https://doi.org/10.1021/acssuschemeng.9b02139.

Reshetnyak EA, Ivchenko NV, Nikitina NA. (2012). Photometric determination of aqueous cobalt (II), nickel (II), copper (II) and iron (III) with 1-nitroso-2-naphthol-3,6-disulfonic acid disodium salt in gelatin films, Central Eur J Chem. 10: 1617 - 1623. https://doi.org/10.2478/s11532-012-0081-7

Sain M, Panthapulakkal S. (2006). Bioprocess preparation of wheat straw fibers and their characterization, Ind. Crops Prod. 23:1 - 8. https://doi.org/10.1016/j.indcrop.2005.01.006.

Sandoval - Flores G, Alvarado - Reyna S, Elvir - Padilla LG, Mendoza - Castillo DI, Reynel - Avila H.E, Bonilla - Petriciolet A. (2018). Kinetics, Thermodynamics, and Competitive Adsorption of Heavy Metals from Water Using Orange Biomass. Water Environ Res. 90 (12): 2114-2125. https://doi.org/10.2175/106143017X15131012188321.

Silva Filho EC, Santos Júnior LS, Fernandes Silva MM, Fonseca MG, Abreu Santana SA, Airoldi C. (2013). Surface cellulose Modification with 2-Aminomethylpyrine for Copper, Cobalt, Nickel and Zinc Removal from Aqueous solution, Mater Res. 16: 79 - 87. https://doi.org/10.1590/S1516-14392012005000147.

Silvestein RM, Webster FX, Kiemle DJ, Bryce DL. (2007). Spectroscometric identification of Organic Compound, $8^{\text {th }}$ edition. Wiley. New York, $81-108$.

Tran VV, Park D, Lee Y-C. (2018). Hydrogel applications for adsorption of contaminants in water and wastewater treatment. Environ Sci Pollution Res. 25: 24569 - 24599. https://doi.org/10.1007/s11356-018-2605-y.

Wang X, Liu P, Liu F, Wang X, Ji M, Song L. (2018). Adsorption Pb (II) by a polyvinylidene fluoride membrane bearing chelating poly(amino phosphoric acid) and poly(amino carboxylic 

https://doi.org/10.1177/0263617418795531.

426 Yao Y, Wang H, Wang R, Chai Y, Ji W. (2019). Fabrication and performance characterization

427 of the membrane from self-dispersed gelation-coupled cellulose microgels, Cellulose, 26, 3255 $428-3269$.

429 Yin OS, Amin MCIM. (2014). Synthesis of chemical cross-linked gelatin hydrogel reinforced 430 with cellulose nanocrystals (CNC), AIP Conference Proceedings, 1614, 375-380. 431 https://doi.org/10.1063/1.4895226.

432 Zhang C, Li H, Yu Q, Jia L, Wan LY. (2019). Poly (aspartic acid) Electrospunnanofiber 433 Hydrogel Membrane-based reusable colorometric sensor for $\mathrm{Cu}$ (II) and Fe (II) detection. 434 Omega. 4: 14633 - 14639. https://doi.org/10.1021/acsomega.9b02109.

\section{Tables}

Table 1. Characteristics of the mining plant effluent used.

\begin{tabular}{lccc}
\hline Parameter & Lower limit & Average & Upper limit \\
\hline $\mathrm{CODs}(\mathrm{mg} / \mathrm{L})$ & $48.0 \pm 0.5$ & $50.0 \pm 0.5$ & $59 \pm 1.5$ \\
$\mathrm{NH}_{4}{ }^{+}(\mathrm{mg}-\mathrm{N} / \mathrm{L})$ & $36.0 \pm 0.5$ & $40.0 \pm 1.5$ & $42 \pm 0.2$ \\
$\mathrm{NO}_{2}^{-}(\mathrm{mg}-\mathrm{N} / \mathrm{L})$ & $0.90 \pm 0.02$ & $0.92 \pm 0.02$ & $0.94 \pm 0.02$ \\
$\mathrm{NO}_{3}^{-}(\mathrm{mg}-\mathrm{N} / \mathrm{L})$ & $4.0 \pm 0.4$ & $6.0 \pm 0.4$ & $10 \pm 0.4$ \\
Total inorganic nitrogen & $40.8 \pm 0.2$ & $45.8 \pm 0.2$ & $54.9 \pm 0.2$ \\
(mg-N/L) & & & \\
Total Phosphorus (mg/L) & $7.8 \pm 0.2$ & $9.0 \pm 0.2$ & $12.0 \pm 0.2$ \\
$\mathrm{pH}$ & $7.0 \pm 0.2$ & $7.2 \pm 0.2$ & $7.4 \pm 0.2$
\end{tabular}

439

Table 2. Composition of GCHM Hydrogel

\begin{tabular}{ccccc}
\hline & Ratio $1 \div 3(\%)$, & Ratio $1 \div 1(\%)$, & Ratio $3 \div 1(\%)$, & Water $(\mathrm{ml})$ \\
& $\mathbf{A}$ & $\mathbf{B}$ & $\mathbf{C}$ & \\
\hline Gelatin & 25 & 50 & 75 & N/A \\
\hline CNCs & 75 & 50 & 25 & 50 \\
\hline
\end{tabular}


Table 3. Calculate values of isotherm parameters, $\mathrm{T}=303 \mathrm{~K}$, Ratio $3 \div 1, \mathrm{Cu}(\mathrm{II})_{\mathrm{pH} 5}$ and $\mathrm{Co}$

(II) $)_{\mathrm{pH} 7}$

\begin{tabular}{lcccccccccc}
\hline Metal ions & \multicolumn{4}{c}{ Langmuir } & \multicolumn{3}{c}{ D-R } & \multicolumn{3}{c}{ Freundlich } \\
\cline { 2 - 11 } & $\mathrm{K}_{\mathrm{L}}$ & $\mathrm{R}_{\mathrm{L}}$ & $\mathrm{q}_{\mathrm{m}}$ & $\mathrm{R}^{2}$ & $\mathrm{E}$ & $\mathrm{q}_{\mathrm{m}}$ & $\mathrm{R}^{2}$ & $\mathrm{n}$ & $\mathrm{K}_{\mathrm{f}}$ & $\mathrm{R}^{2}$ \\
\hline Copper (II) & 0.03 & 0.23 & 5.85 & 0.88 & 5.49 & 10.26 & 0.68 & 0.83 & $1.89 \times 10^{3}$ & $\mathbf{0 . 8 9}$ \\
Cobalt (II) & 0.05 & 0.16 & 10.99 & 0.87 & 7.91 & 15.34 & 0.79 & 1.31 & $3.7 \times 10^{2}$ & $\mathbf{0 . 9 4}$ \\
\hline
\end{tabular}

Table 4. Kinetic parameters for $\mathrm{Cu}(\mathrm{II})_{\mathrm{pH} 5}$ and $\mathrm{Co}(\mathrm{II})_{\mathrm{pH} 7}$ adsorption onto GCHM (ratio: $3 \div 1$ ), concentration: $100 \mathrm{mg} / \mathrm{L}$, dosage: $0.25 \mathrm{~g} / 100 \mathrm{~mL}$, temperature $30^{\circ} \mathrm{C}$.

\begin{tabular}{lccc}
\hline \multicolumn{4}{c}{ First order } \\
\hline Copper (II) & $\mathbf{q}_{\mathbf{e}}$ & $\mathbf{k}_{\mathbf{1}}$ & $\mathbf{R}^{\mathbf{2}}$ \\
Cobalt (II) & 25.40 & $3.22 \times 10^{-6}$ & $\mathbf{0 . 9 8}$ \\
\hline & 43.45 & $3.81 \times 10^{-4}$ & $\mathbf{0 . 9 1}$ \\
\hline Copper (II) & $\mathbf{\mathbf { q } _ { \mathbf { e } }}$ & Second order & $\mathbf{R}^{\mathbf{2}}$ \\
Cobalt (II) & 27.86 & $\mathbf{k}_{\mathbf{2}}$ & 0.97 \\
\hline
\end{tabular}

449

450 451

\begin{tabular}{llcc}
\hline & Kinetic diffusion model-Equation & Constant & $\mathbf{R}^{\mathbf{2}}$ \\
\hline Copper (II) & Moving boundary & 0.017 & 0.86 \\
\hline & Particle diffusion & 0.021 & 0.95 \\
& Film diffusion & 0.032 & $\mathbf{0 . 9 8}$ \\
\hline Cobalt (II) & Moving boundary & 0.017 & 0.85 \\
& Particle diffusion & 0.035 & 0.89 \\
& Film diffusion & 0.046 & $\mathbf{0 . 9 1}$
\end{tabular}

Table 5. Adsorption mechanism kinetic parameters for $\mathrm{Cu}(\mathrm{II})_{\mathrm{pH} 5}$ and $\mathrm{Co}(\mathrm{II})_{\mathrm{pH} 7}$ adsorption onto GCHM

\begin{tabular}{|c|c|c|c|c|c|}
\hline Metal & Temperature (K) & $\mathbf{K}_{\mathbf{d}}$ & $\Delta \mathrm{G}^{\circ}(\mathrm{kJ} / \mathrm{mol})$ & $\Delta H^{\circ}(\mathrm{kJ} / \mathrm{mol} \mathrm{K})$ & $\Delta \mathrm{S}^{\circ}(\mathrm{kJ} / \mathrm{mol} \mathrm{K})$ \\
\hline \multirow[t]{4}{*}{$\mathrm{Cu}$ (II) } & 303 & 1.05 & -0.11 & 32.73 & 108.08 \\
\hline & 318 & 1.80 & -1.56 & & \\
\hline & 333 & 3.29 & -3.29 & & \\
\hline & 348 & 5.62 & -4.99 & & \\
\hline
\end{tabular}




\begin{tabular}{llllll}
\hline Co (II) & 303 & 0.86 & 0.39 & 34.23 & 111.32 \\
& 318 & 1.60 & -1.24 & \\
& 333 & 2.53 & -2.57 & \\
& 348 & 5.26 & -4.81 & \\
\hline
\end{tabular}

454

455

456

457 
Figures

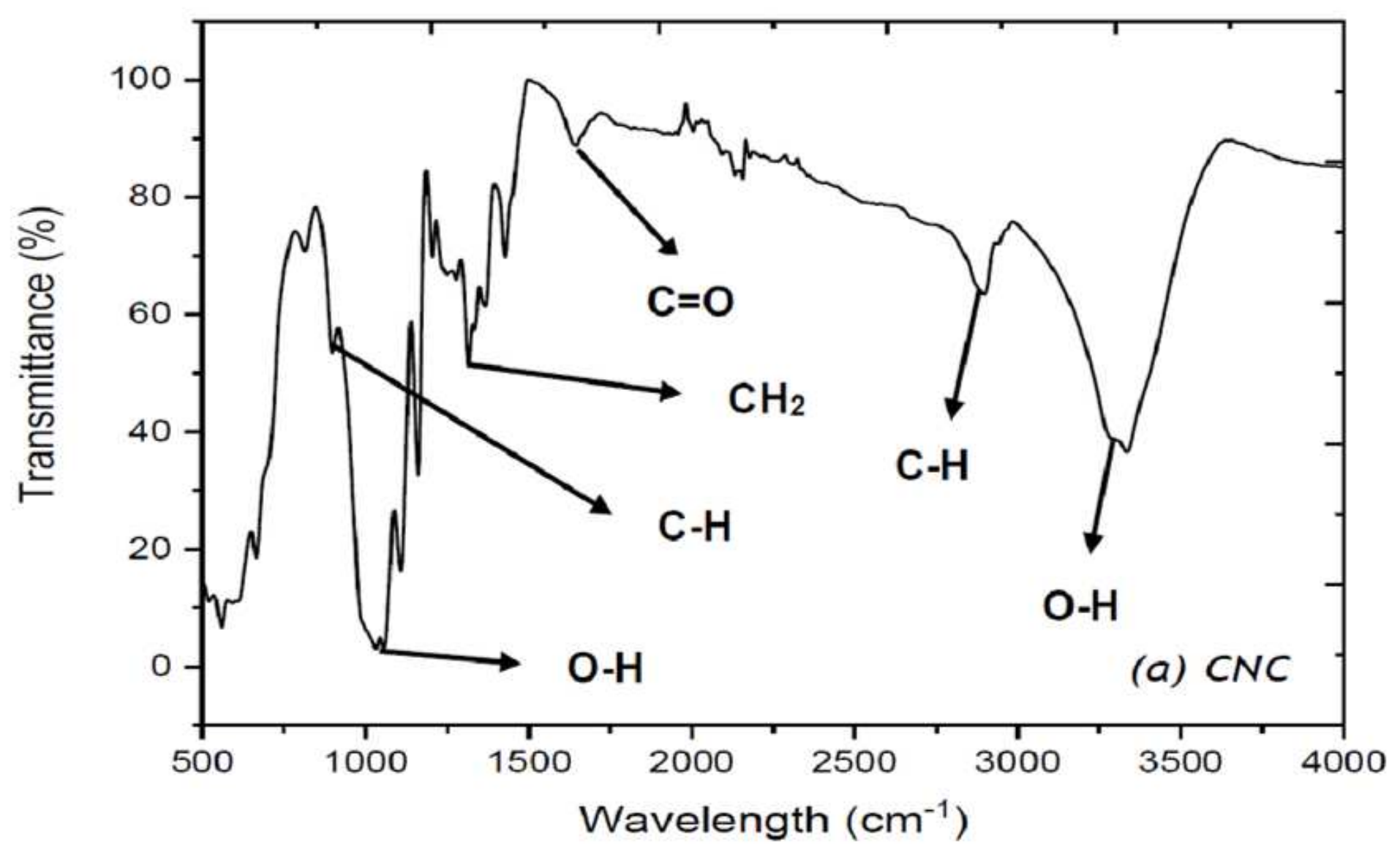

Figure 1

Spectra FTIR of CNCs 


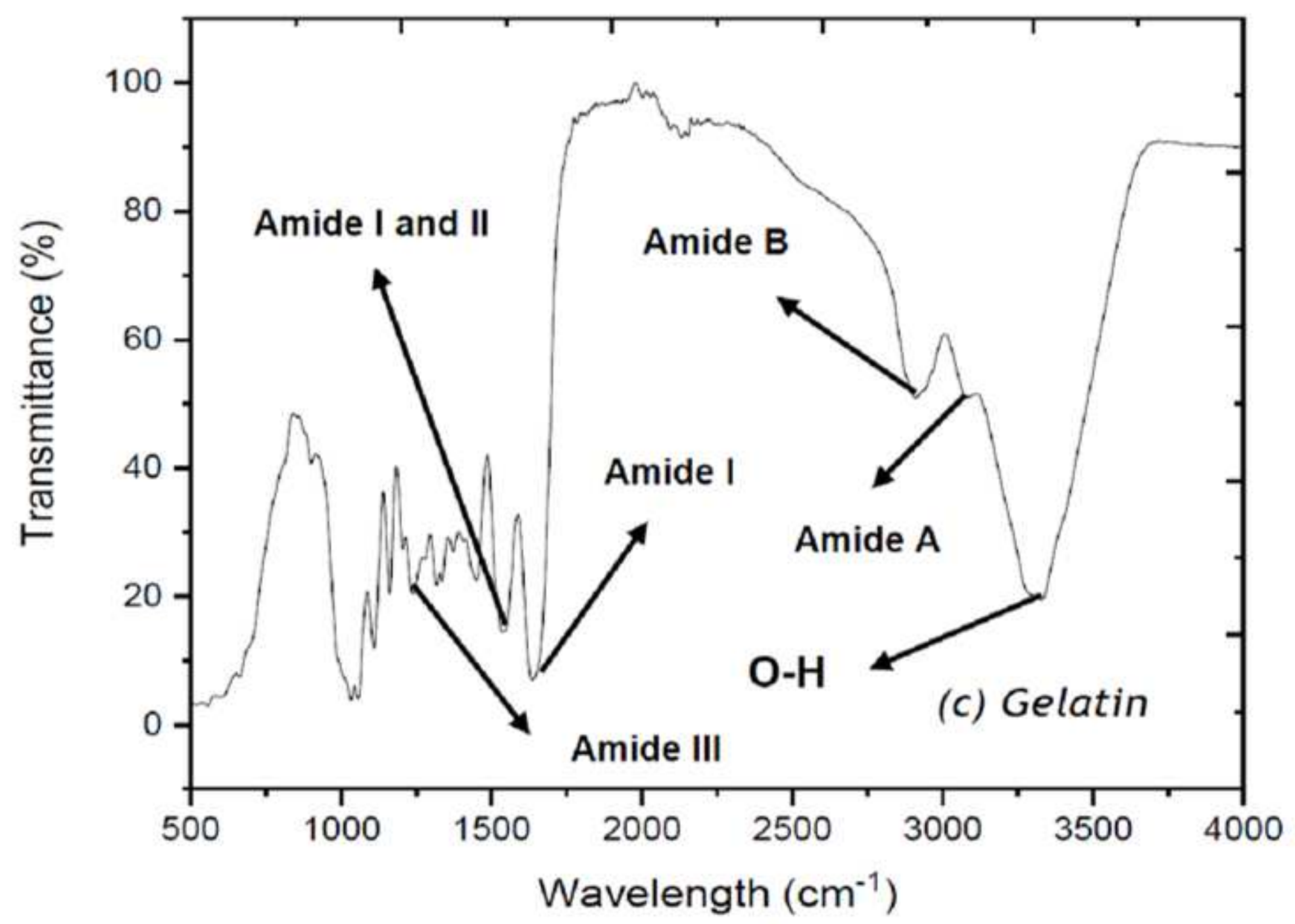

Figure 2

Spectra FTIR of gelatin 


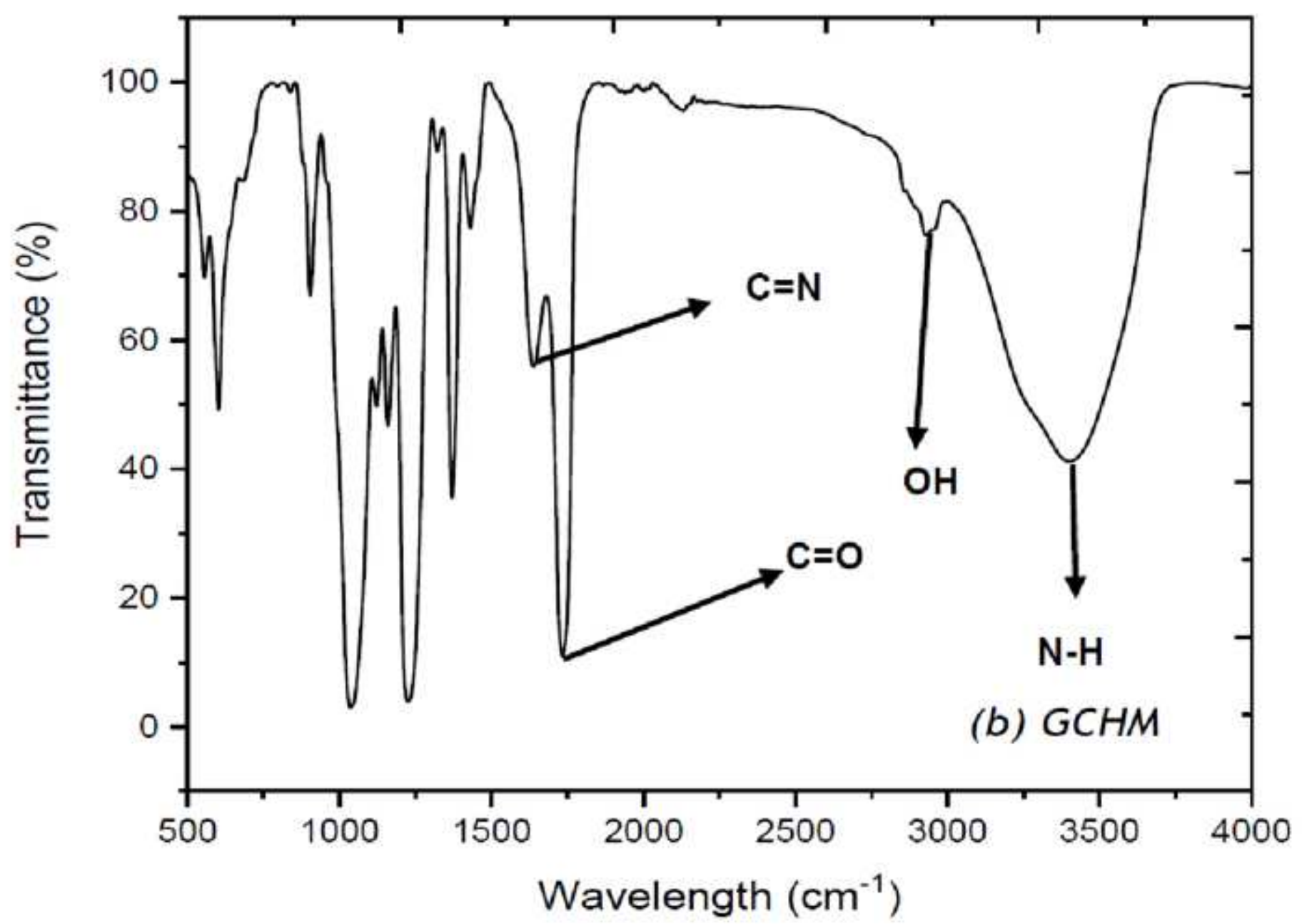

Figure 3

Spectra of Hydrogel at a ratio of $25 \div 75 \%$ 


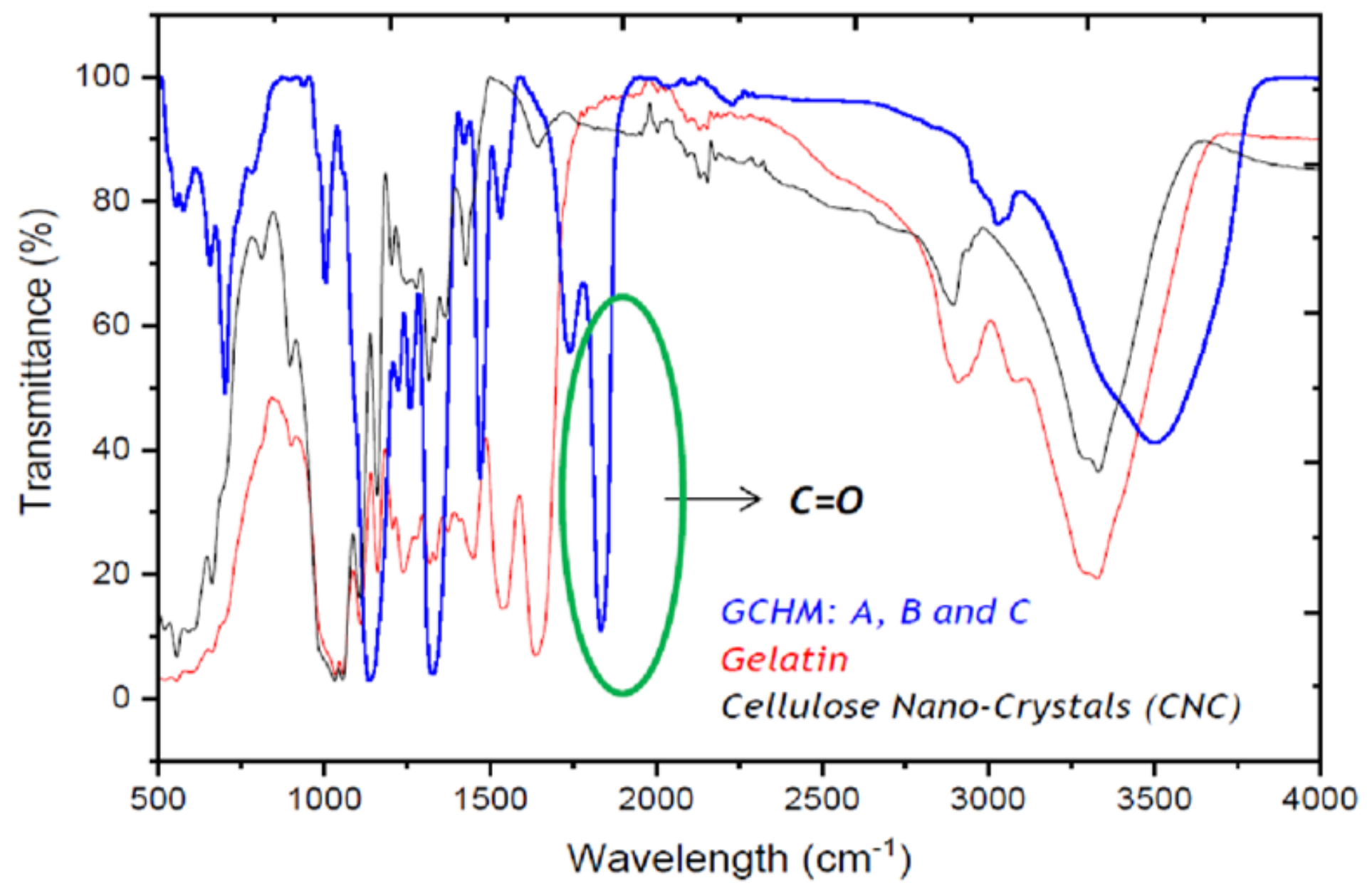

Figure 4

Spectra of CNCs, Gelatinand, GCHM 

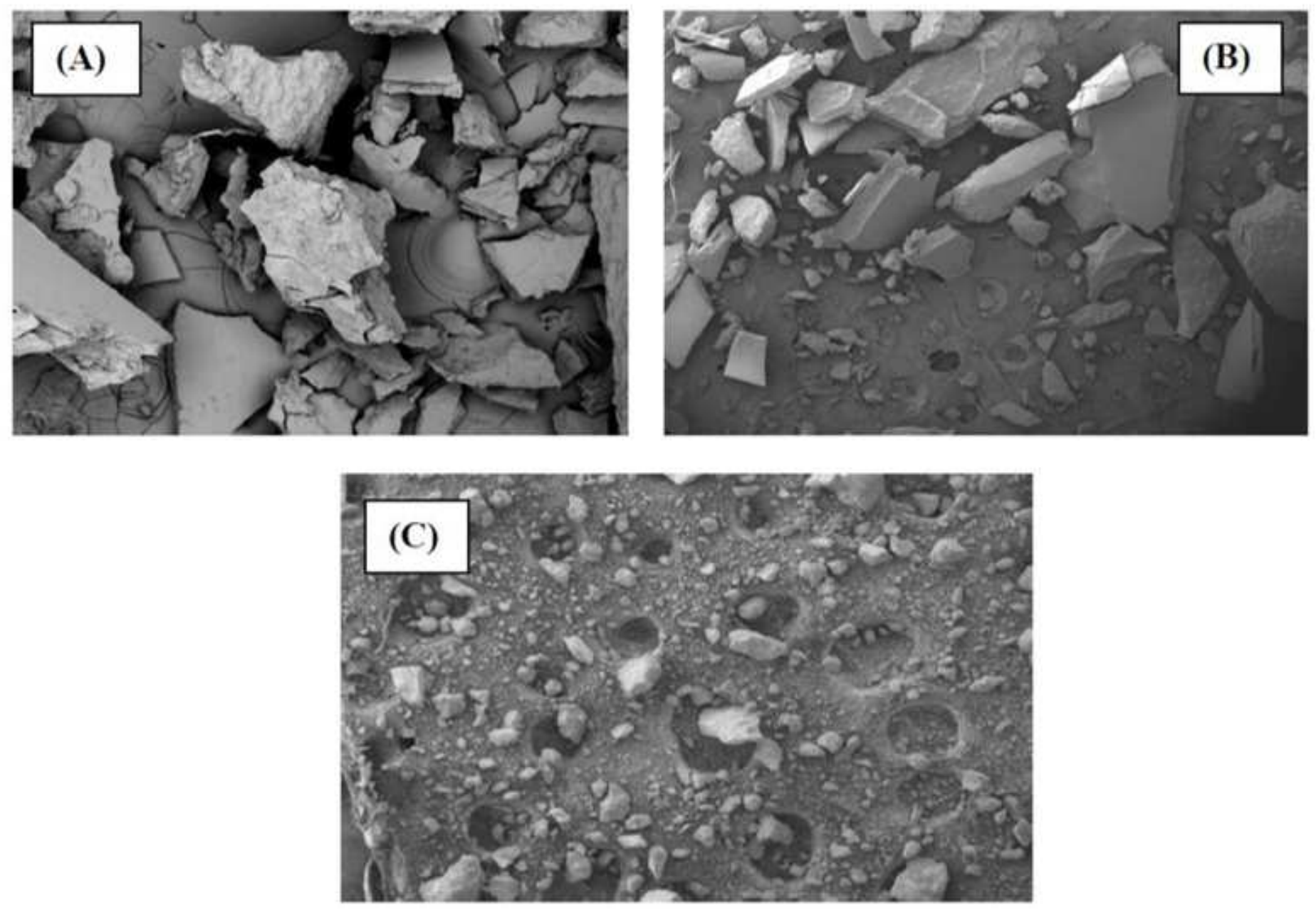

\section{Figure 5}

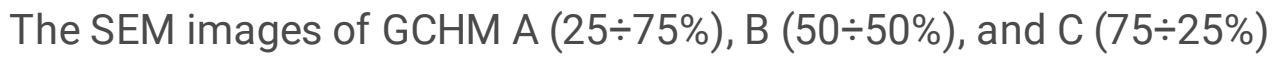




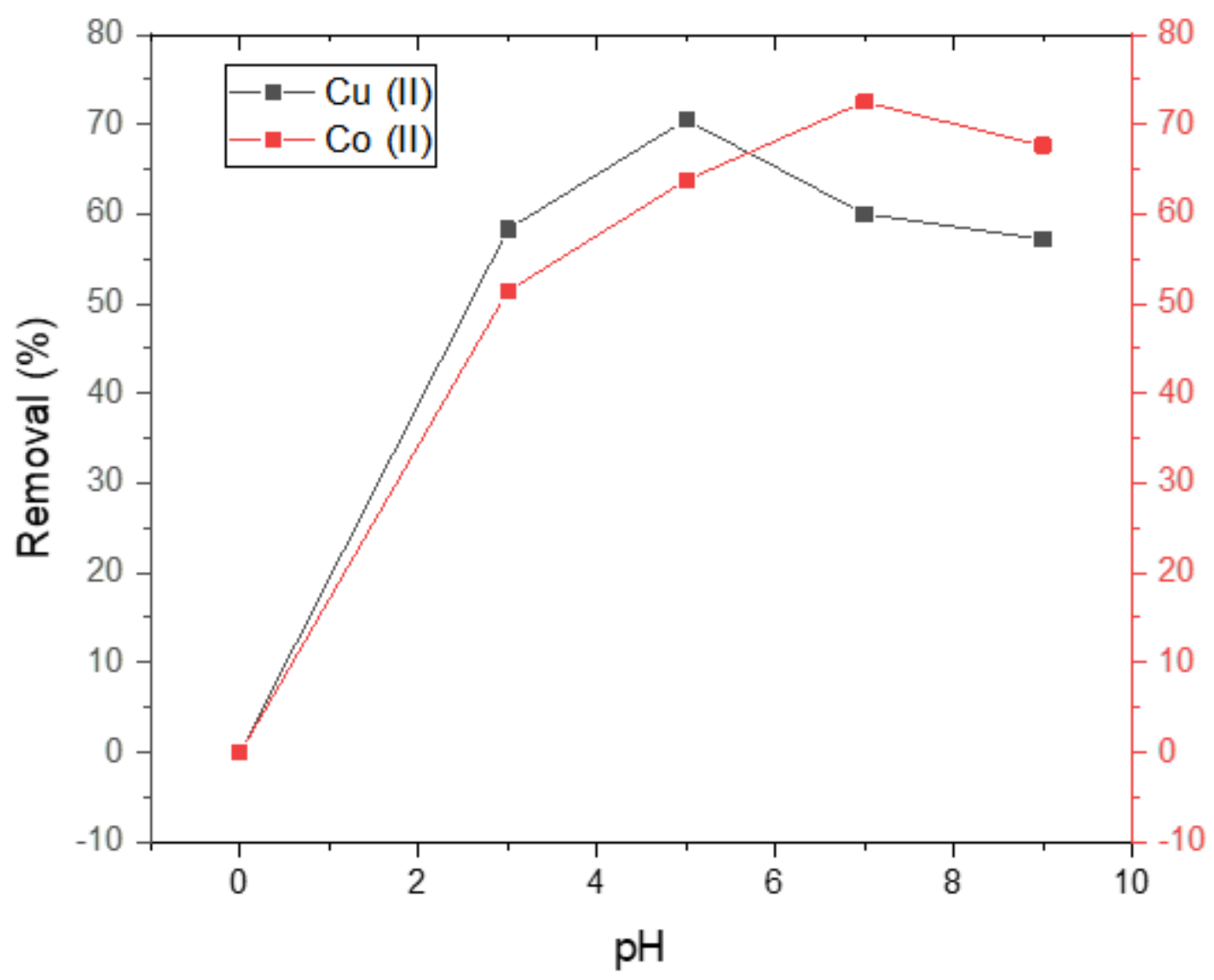

Figure 6

Effect of $\mathrm{pH}$ on the removal of $\mathrm{Cu}$ (II) and Co (II), Ratio $3 \div 1$ at $30 \mathrm{oC}$
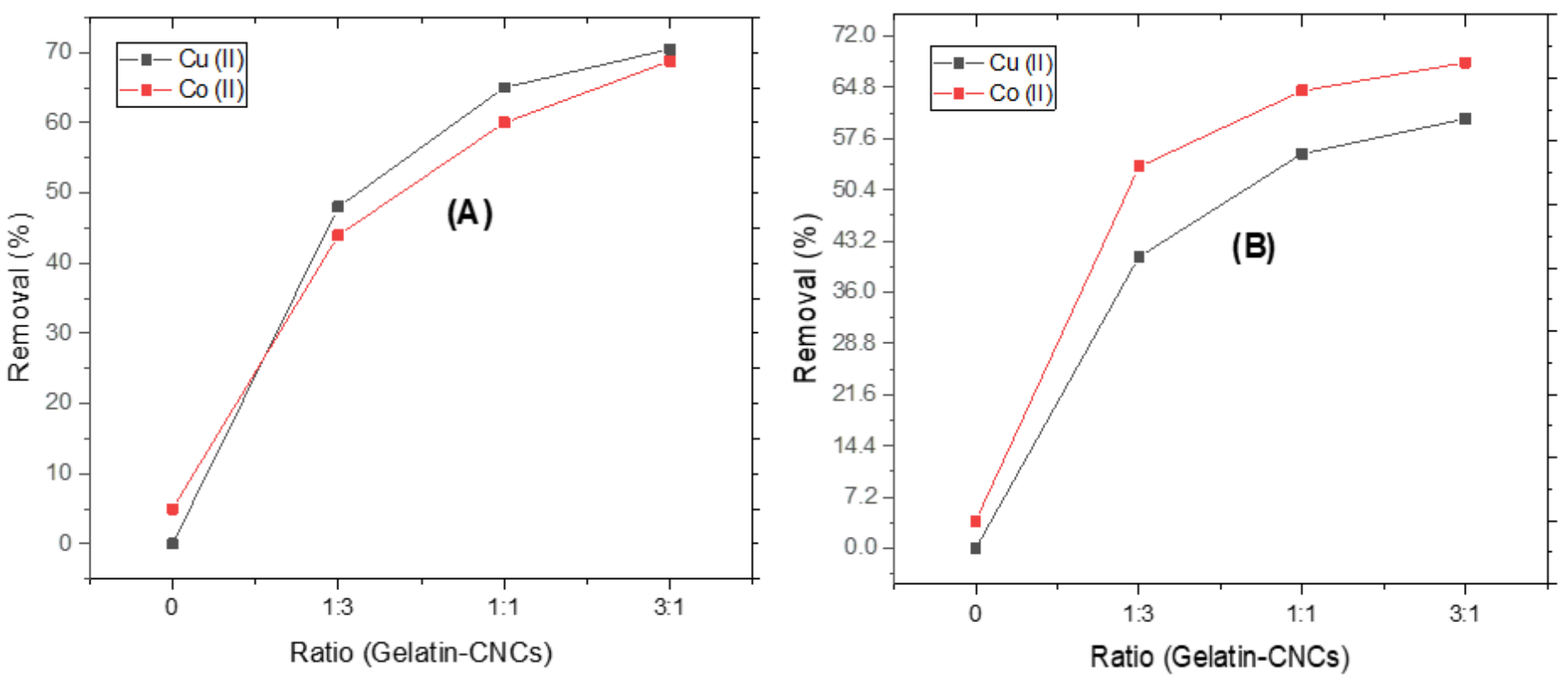

Figure 7

Effect of ratio on percentage removal of $\mathrm{Cu}$ (II) and $\mathrm{Co}$ (II), $\mathrm{pH} 5$ (A) and pH 7 (B), 120 min at 30oC 

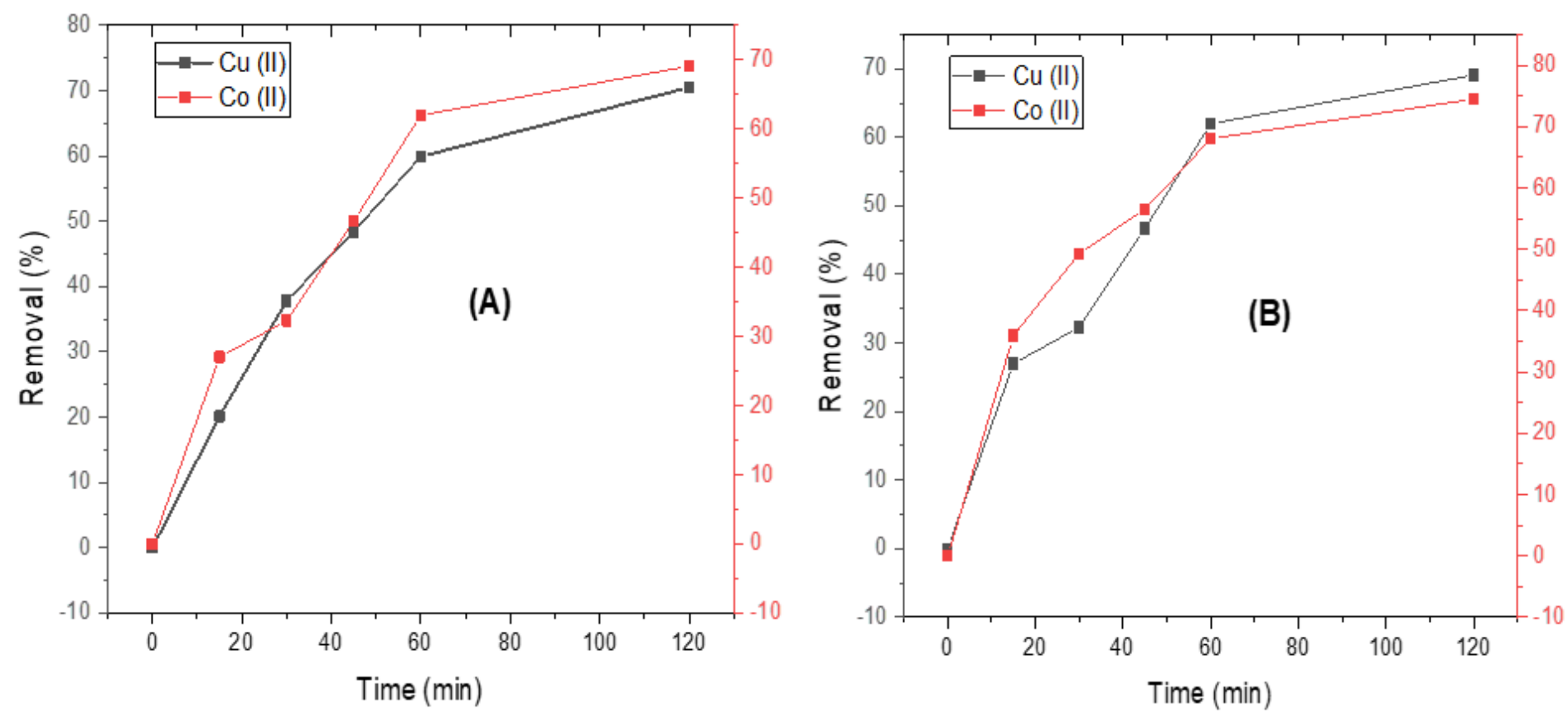

Figure 8

Effect of Time on removal of $\mathrm{Cu}(\mathrm{II})$ and $\mathrm{Co}(\mathrm{II})$, Ratio $3 \div 1, \mathrm{pH} 5$ (A) and pH 7 (B) at 30oC
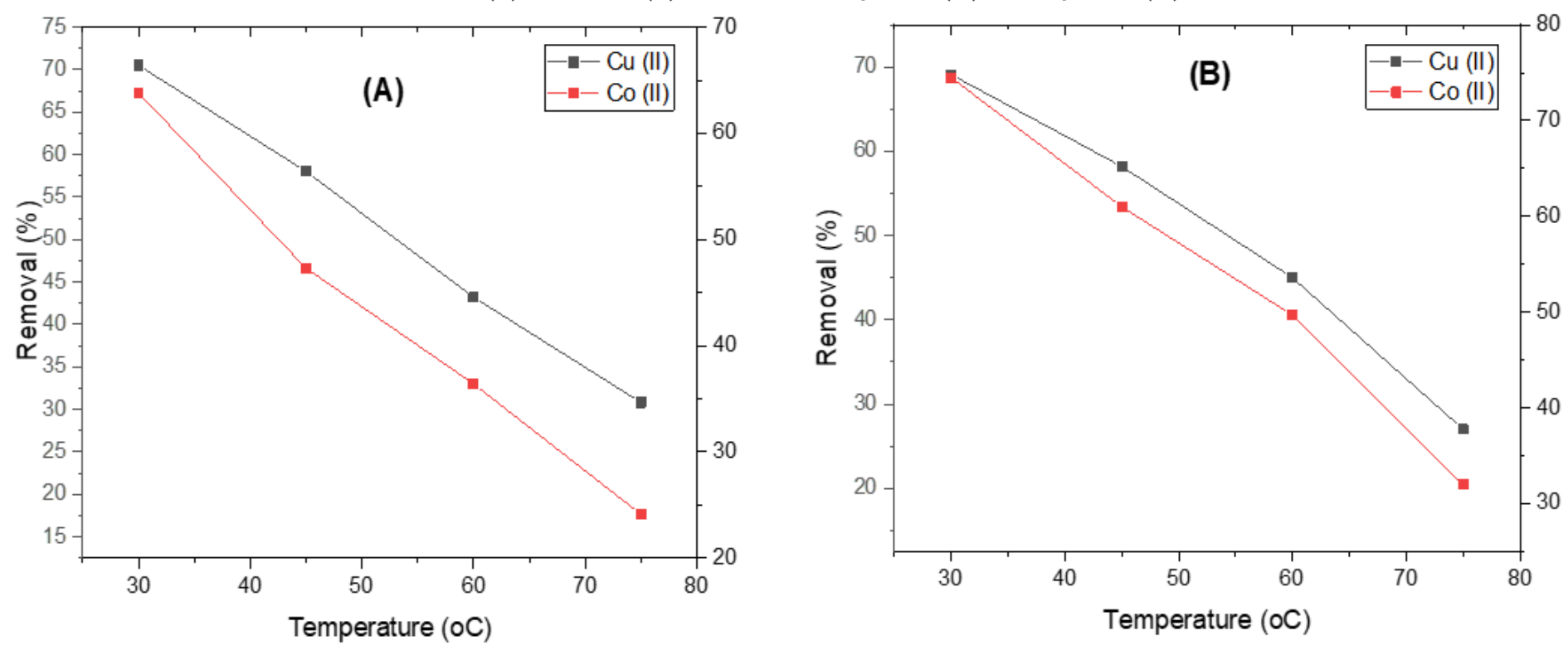

Figure 9

Effect of Temperature on the removal of $\mathrm{Cu}(\mathrm{II})$ and $\mathrm{Co}(\mathrm{II})$, Ratio $3 \div 1, \mathrm{pH} 5(\mathrm{~A})$ and $\mathrm{pH} 7$ (B) 